\title{
Women Behind the U.K Prison Walls: Does the Current Female Prison System Meet Female Prisoners' Needs?
}

\author{
Ashley Mary McCarthy* \\ Volunteer Assistant Psychologist, Glanmire, Co.Cork, Ireland
}

Received: October 20, 2014; Accepted: November 25, 2014; Published: December 18, 2014

*Corresponding author: Ashley Mary McCarthy, Volunteer Assistant Psychologist, Glanmire, Co.Cork, Ireland, Tel: 00-353-857459263; E-mail: ashley3090@gmail.com

\begin{abstract}
This review is based on the research which is concerned with the effects of prison that has on women in England and Wales. More specifically, it looks at whether the current female UK prison system meets female prisoner's gender specific needs. It also looks at offender's mental health. The data collection for this research was done through several secondary sources; the secondary data collected was classified into both quantitative and qualitative data. It concludes that women needs are not always met in the thirteen women prisons in England and Wales; it also draws the conclusion that exploring alternatives to prison for women is necessary. Finally, it highlights that more constructive action needs to be taken in this area with regards to the UK prison system.
\end{abstract}

\section{Research Aims}

1. To research the historical establishment of prisons and examine their progression over time.

2. To investigate whether the current prison system in the United Kingdom (U.K.) was suitable and could potentially meet the needs of female offenders in the U.K.

\section{To explore other alternatives to prisons.}

Quantitative and qualitative secondary data on the treatment of female prisoners and an alternative to prison were used. These were then analyzed in relation to female prisoners in the U.K and female re-offending rates. This data came from a range of sources including books, journal articles, Ministry of Justice prison statistics and newspaper articles.

\section{Justifications}

One reason behind this research was that "many criminologists and women's rights groups attribute the importance of female prisoners needs, not being met to have a detrimental effect on female inmates during their prison stay; arguing that female offenders are slipped into a system which frequently does not meet their needs" [1] ("The U.K Prison System Designed by Men, for Men").
Another reason behind this research resulted from a statement made by Baroness Corston in the 2007 Corston Report, which was commissioned by the Government. "The report provides a critique treatment of women in the criminal justice system and sets out a series of recommendations for reform". The key message was that "prison is not the right place for the vast majority of women offenders who pose no risk to the public". Baroness Corston also stated in her report that "women have been marginalized within a system largely designed by men for men for far too long" [2].

\section{Methodology}

This research was carried out to investigate whether the current prison system in the UK is suitable when it comes to meet the needs of female offenders. The secondary data took the form of both quantitative and qualitative data [3]; for example, statistics on female prisoners, both sentenced and on remand in England and Wales and on re-offending rates, research on the treatment of female prisoners such as dealing with women who may have specific mental health issues, and on alternatives to female imprisonment. Although, it would have been ideal to gather primary data to explore first - hand, unfortunately there was time and resource restrictions. Secondary data analysis is the use of data that was collected by someone else. A major advantage of secondary data is its wide range of availability. This piece of research includes literature and data from various books, organizations and reports, for example criminology theory books, the Quakers organization [4], the Women In Prison organization [5], the Prison Reform Trust organization [6], the Bromley briefing reports [7], the Corston report [2], the Bangkok rules from the UN Penal Reform International [8] which promotes fair and effective criminal justice and the Ministry of Justice [9].

\section{Literature}

The research looked at female offenders by assessing female criminality historically, by looking at the causes, characteristics and extent of female criminality in the UK and also by looking at the treatment of female offenders as well as the importance of their mental health. 
It evaluates and discusses treatment of women in prison based on the following topics:

a) Mental health provision in female prisons,

b) Mother and baby units,

c) Geographical location of female prisons -are they centrally located enabling women to keep contact with their family and children,

d) Programmes in female prisons education and work provision in female prisons, and

e) Seriousness of offences that warrant imprisonment

\section{Mental Health of Female Offenders}

It is important to note that research on mental health in female prisoners highlight that mental health issues are often exacerbated by the prison experience. First, let us discuss some of the facts and figures regarding mental health and self- harm. The organization Women In Prison (WIP) aims to "develop a range of services and interventions that limit, and where possible, to prevent the damage and disruption done to women as a result of their contact with the criminal justice system" in the UK (Women In Prison, About us). "83\% of women in prison stated that they had long-standing illness, compared with $32 \%$ of the general female population." In 2012, "47\% of female offender population suffered from a major depressive disorder, 6\% suffered from psychosis and 3\% had schizophrenia" [10]. Also, it is shocking to see that "women accounts for $47 \%$ of all incidents of self- harm" [10].

While the root causes of suicide and self-harm in prisons are complex, Lauren Harkey [11] states that a number of potential risks that can cause women to attempt suicide or self-harm whilst in prison are: "history of sexual or violent abuse, lack of control of their life whilst in prison, living in care as a child, brake down of family ties, and drug or alcohol problems" [11]. Further studies according to Harkey have found that vulnerability; deprivations while in prison and prison overcrowding exacerbate suicidal and self-harm feelings and tendencies [11]. Overcrowding in women prisons have been found to increase feelings of stress and uncertainty as prisoners may fear each other. It should be a priority of the prison staff to ensure that women are made feel safe and not fearful whilst in prison.

An important component of change in the current mental health care provisions would be to ensure that prisoners and prison staff whether it is prison guards or counselors can form a relationship based on trust and care for prisoners. Maureen Mansfield recorded personal accounts from women in UK prisons based on their opinions of a day in the life of prison. One prisoner expressed that "I don't think the officers give enough support to prisoners and their attitudes stink. We have lots of people that require special needs but they are not always catered for", a second prisoner stated that, they personally saw and heard about them saying "women with mental health issues clearly are not always cared for properly" [12]. As previously stated a lot of women in prison have been abused in some shape or form during their lives and many have been let down by the social care system, therefore are often in very vulnerable mental states. Another important note that needs to be taken in to consideration in the future is that the UK government must ensure that gender specific policies in relation to mental health provisions are a priority and ensure that enough trained individuals are employed at each woman's prison in England and Wales to help try and prevent these vulnerable women from falling through the cracks resulting in situations of worthlessness, self-harm or self- inflected death. However, making the much needed changes cannot be viewed as the responsibility of individual prisons alone; it is the responsibility of the entire criminal justice system and, in particular, of central government through its Ministry of Justice (Figures 1 and 2).

\section{Conclusions}

This paper highlights more about the constructive action that needs to be taken in the U.K prison system. Problems that need to be dealt with are mental health issues due to the overwhelming numbers of prisoners that self-harm and attempt suicide. Other issues include the seriousness of crimes that warrant a prison sentence versus a community sentence or court ordered treatment as punishment.

Women in prison have the right to a safe and secure environment, and to feel heard by prison staff. They need to receive adequate treatment whether for drug and/or alcohol addictions or for mental illnesses. They need to be placed in geographical locations that allow families and children the access they deserve. They also need to acquire practical skills to help them on release to break the revolving door pattern of prison.

\section{U.K Prison population Chart (2013)}

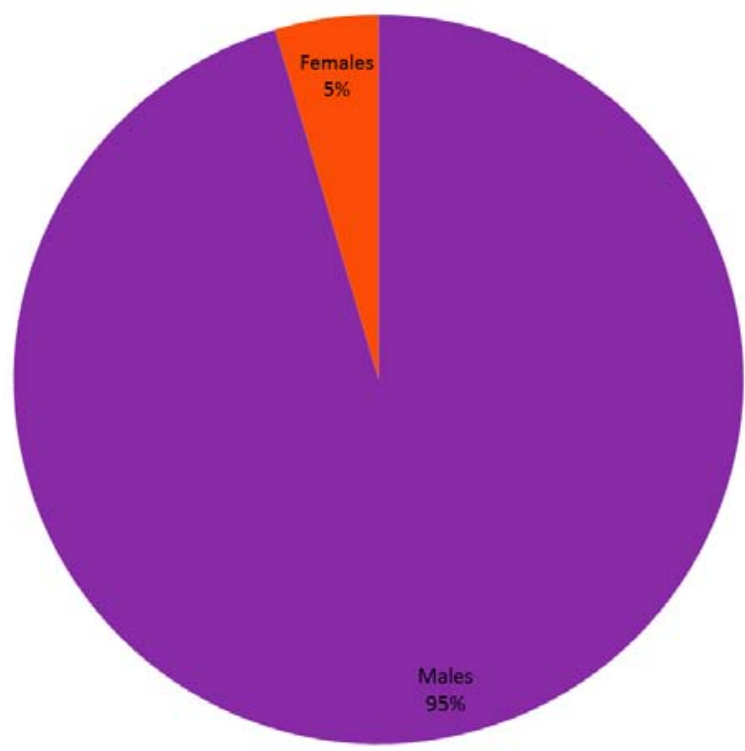

Figure 1: UK Female \& Male Prison Population. 

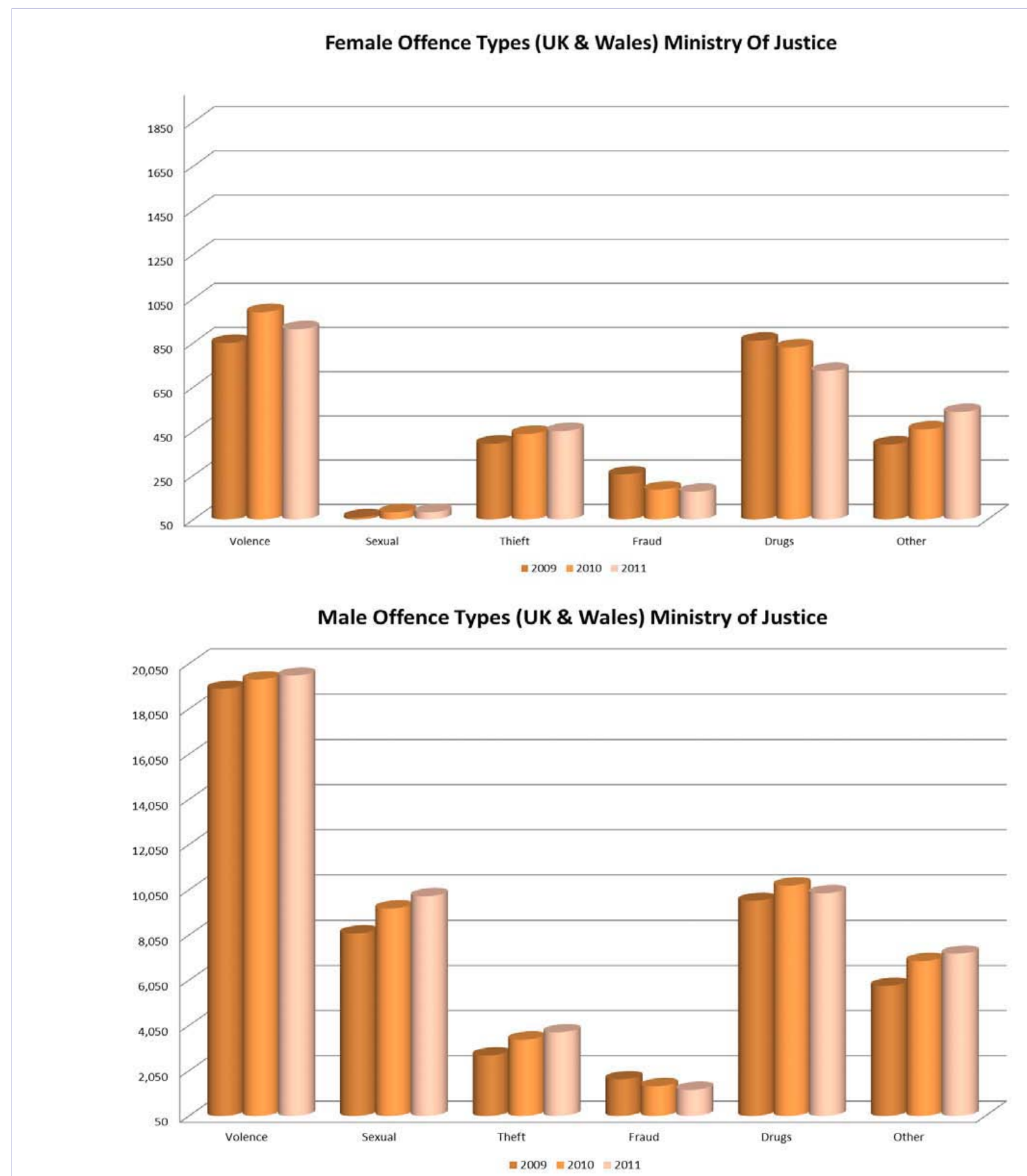

Figure 2: Female \& Male offense Types (Violence, Sexual, Theft, Fraud, Drugs and others). Data's from 2009-2011.

Carlen and Worrall [13] stated that "Women's prisons are inappropriately modeled on institutions designed for men". This fact is still apparent even several years after the work of Carlen and Worrall.

Mothers and children are being split up unnecessarily in the current U.K criminal justice system causing long lasting negative psychological effects on the whole family.
The majorities of female prisoners are drug addicts, alcoholics, poorly educated and are often in poverty situations before they land in prison custody. The crimes they commit are mostly non-violent; therefore prison may not be a suitable place for these vulnerable women.

The women's Justice Task Force [14] along with other scholars and support services such as Women in Prison argue 
that "Custody proves ineffective in the majority of cases and it is also expensive. In contrast community based punishments tend to be more effective and are more cost effective". For many women, prison is an emotionally costly place, one far greater than the crime they committed.

The Corston Report strongly recommended that "women's prisons to be scrapped and replaced by a number of smaller units to house those the criminal justice system fell still need to serve a custodial sentence". This is very important as the development of smaller units would mean that they could be more strategically and geographically placed so that women would not suffer the trauma of losing the support of their families.

The U.K Government should ensure that a crime is punished appropriately and proportionally with adequate support and rehabilitation available to all women. This is achievable if the government and prison services come together and stick to a gradual redevelopment of sentencing guidelines for women.

From this research it is evident that the UN Bangkok Rules are very important as they recognize that "the majority of female prisoners do not pose a risk to society" and also that women often have responsibilities for children therefore the best interest of the child must be given priority. The purpose of the rules was an attempt to highlight the importance of the differentiated needs of the growing number of female prisoners [12]. The U.K. government needs to ensure that every woman's prison sticks rigidly to the 70 Bangkok rules.

According to Ministry of Justice research, "comparing similar offenders and similar offences, shows that community sentences are now outperforming short prison sentences and are $8.3 \%$ more effective in reducing re-offending rates" [15]. Effective community sentences are an adequate alternative for some offenders namely those who are non-violent.

Prisons should only be used, a) as a last resort and b) only for women who have committed violent offences and are therefore a threat to society.

\section{References}

1. Hackney L. Was the prison system designed by men for men? Internet
Journal of Criminology. 2011: 1-3.

2. Corston J. The Corston Report: A Review of Women with Particular Vulnerabilities in the Criminal Justice System. London: Home Office; 2007.

3. Patton MQ, Cochran M. A guide to using Qualitative research methodology. MSF Field Research. 2002: 2-3.

4. Bastick M, Townhead L. Women In Prison: A commentary on the UN standard minimum of prisons. Geneva: Quakers United nations office; 2011.

5. Nick Hardwick. Women In Prison: Corston Report Five years on. The University of Sussex: Issues in Criminal Justice. 2012.

6. Prison Reform Trust response to Justice Committee Inquiry on Women Offenders. London: Prison Reform Trust. 2000.

7. Prison: the facts Bromley Briefings summer. Prison Reform Trust. 2013: 11 .

8. Penal Reform International. UN Bangkok Rules. Available from: http://www.penalreform.org/priorities/women-in-the-criminaljustice-system/bangkok-rules-2/

9. Ministry of Justice. Women Prisoners. Available from: http://www. justice.gov.uk/offenders/types-of-offender/women

10.Women In Prison. Statistics. Available from: https://www. womeninprison.org.uk

11. Harkey LS. Does overcrowding in prisons exacerbate the risk of suicide among women prisoners? The Howard Journal of Criminal Justice. 2010; 49(2): 111-112. doi: 10.1111/j.1468-2311.2009.00602.x.

12. Women In Prison. State of the Estate: Women in Prison's report on the women's custodial estate. 2012: 9.

13. Carlen P, Worral A. Alternatives to custody. Analysing Women's Imprisonment. Oregon: Willan Publishing; 2004. p. 118.

14. Reforming Women's Justice. Final report of the Women's Justice Taskforce. London: Prison Reform Trust; 2011.

15. Response to the Ministry of Justice consultation, Punishment and reform: effective community sentences. London: Prison Reform Trust: 2011. p. 5-6. 